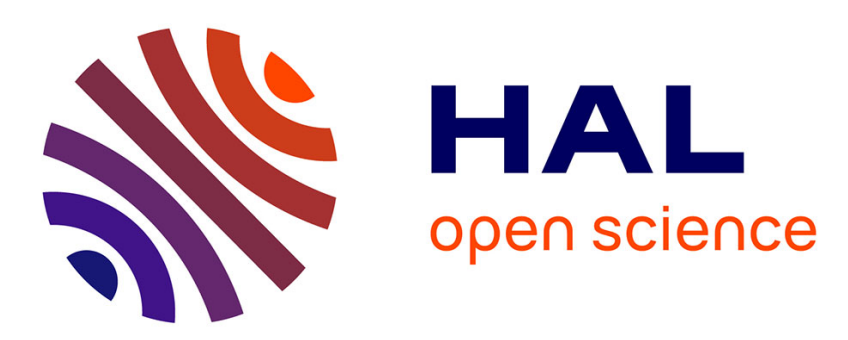

\title{
Density of state anisotropy study in $\eta$ Mo4011 below Peierls' transition by tunneling effect
}

\author{
J. Sorbier, H. Tortel, A. Fournel, I. Oujia
}

\section{To cite this version:}

J. Sorbier, H. Tortel, A. Fournel, I. Oujia. Density of state anisotropy study in $\eta$ Mo4O11 below Peierls' transition by tunneling effect. Journal de Physique IV Proceedings, 1993, 03 (C2), pp.C2-259-C2-262. 10.1051/jp4:1993252 . jpa-00251335

\section{HAL Id: jpa-00251335 https://hal.science/jpa-00251335}

Submitted on 1 Jan 1993

HAL is a multi-disciplinary open access archive for the deposit and dissemination of scientific research documents, whether they are published or not. The documents may come from teaching and research institutions in France or abroad, or from public or private research centers.
L'archive ouverte pluridisciplinaire HAL, est destinée au dépôt et à la diffusion de documents scientifiques de niveau recherche, publiés ou non, émanant des établissements d'enseignement et de recherche français ou étrangers, des laboratoires publics ou privés. 


\title{
Density of state anisotropy study in $\eta \mathrm{Mo}_{4} \mathrm{O}_{11}$ below Peierls' transition by tunneling effect
}

\author{
J.P. SORBIER, H. TORTEL, A. FOURNEL and I. OUJIA
}

Laboratoire d'Electronique des Milieux Condensés, UR 28, Université de Provence, Centre de Saint-Jérôme, 13397 Marseille cedex 13, France

\begin{abstract}
We study here the evolution with temperature of the $\eta$ Mo4O11 density of state in different crystallographic directions by tunneling effect. We have pointed out that the evolution of the condensation rate and the width of the pseudo-gap is anisotropic.
\end{abstract}

\section{INTRODUCTION :}

$\eta$ Mo4O11 is with $\gamma$ Mo4011 and Mo8O23 a molybdenum oxyde compound of the MonO3n- 1 family. Its crystalline structure may be represented like an infinite stacks of MoO6 octhaedra separated by planes of MoO4 thetrahedra (ref. 1).

Transport properties have been studied for the first time in 80's. This compound presents a charge density wave transition towards $100 \mathrm{~K}$ and a second metalsemiconducting along $b$ axis transition around $30 \mathrm{~K}$. (ref 2). The type of this second transition is not well defined to our knowledge. The charge density wave transition (CDW) opens in a one dimensionnal crystal a semiconducting gap in a particular crystallographic direction, also called the nesting direction, and is always accompanied by a periodic lattice distorsion (PLD).

The monoclinic molybdenum oxyde is a quasi bidimensionnal crystal,(b c) plane is the higly conducting plane, transport properties are very anisotropic along its crystallographic axis. The CDW transition appears at $98 \mathrm{~K}+/-2 \mathrm{~K}$. The wave vector value of the PLD is $0,23 b^{*}$.

Tunneling experiments seems all indicated here to study the evolution with temperature of the density of states in the Fermi level neighbouring for different 
crystallographic orientation.

\section{EXPERIMENTAL TECHNIQUE :}

Tunneling junctions are prepared by using a classical technique.After having washed crystals in arnmonia solution, dots of lead are evaporated in vacuum $\left(10^{-6}\right.$ Torr) on different natural faces. An insulating barrier of few $A$ is naturally made at the interface separating the materials. The junction quality has always been verified by observing the classical superconductive lead gap at $4,2 \mathrm{~K}$ and $1 \mathrm{~K}$, as shown in left insert in figure 1 . The superconductivity is then suppressed by applying a $2 \mathrm{kG}$ magnetic field.

The crystallographic directions have been characterized under an optical microscope and by comparaison of conductivity measurements along an axis wich contain ohmic contacts and the lead dots, with results published in litterature (ref 1). The typical evolution for different temperatures of $d V / d l$ versus bias voltage is represented in figure 1.

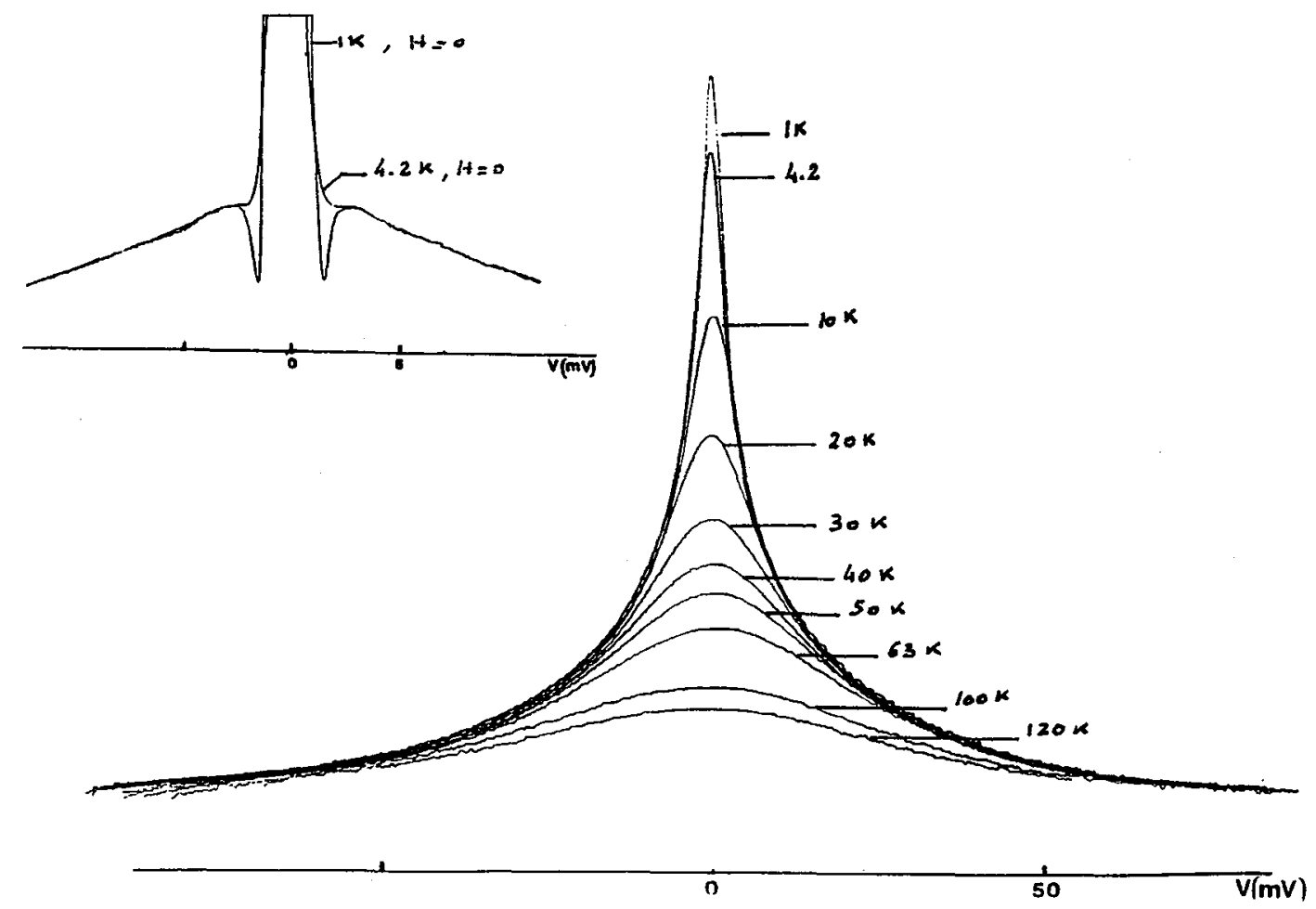

figure 1 : evolution of $d V / d$ for various temperature. (left insert : superconductive gap of lead at $4.2 \mathrm{~K}$ and $1 \mathrm{~K}$. 


\section{RESULTS AND DISCUSSION :}

It's well known that the density of states $N(E)$ can be obtained by first derivate of tunneling current versus applied voitage (ref 2 ). For an experimental reason we plot the inverse $d V / d l$. We have chosed the $d V / d l$ curve at $100 \mathrm{~K}$ in figure 1 as ground base. If we compute the inverse of difference between different curves and ground base, we obtain the density of state evolution for different temperatures. The condensation rate is described in figure 2 ..The condensation at Fermi level is the most important when the junction plane is perpendicular to a axis and ohmic contacts are along $b$ axis or in other hand that tunneling current is contained in $a b$ plane (curve 1). In this case the width at half height of the tunneling density of state at $1 \mathrm{~K}(2 \Delta)$ is less important and is typically equal to $15 \mathrm{mV}+/-2 \mathrm{mV}$. At the opposite, when tunneling current is contained in bc plane (curve 3) the condensation at Fermi level is the slowliest and the value of $2 \Delta$ is the largest (typically $30 \mathrm{mV}+1-2 \mathrm{mV}$ ). The curve $\mathrm{n}^{\circ} 2$ represents the case where junction plane is perpendicular to a axis and ohmic contacts being along $c$ axis (tunneling current is along ac plane), the value of $2 \Delta$ is also $30 \mathrm{mV}+1-2 \mathrm{mV}$. If we compare the evolution of condensation rate in orthorombic molybdenum bronze, as shown ,in figure 2 ,we remarks that the tunneling characteristics are quasily independent of crystalline orientation. This result is coherent with conductivity curves obtained with this material

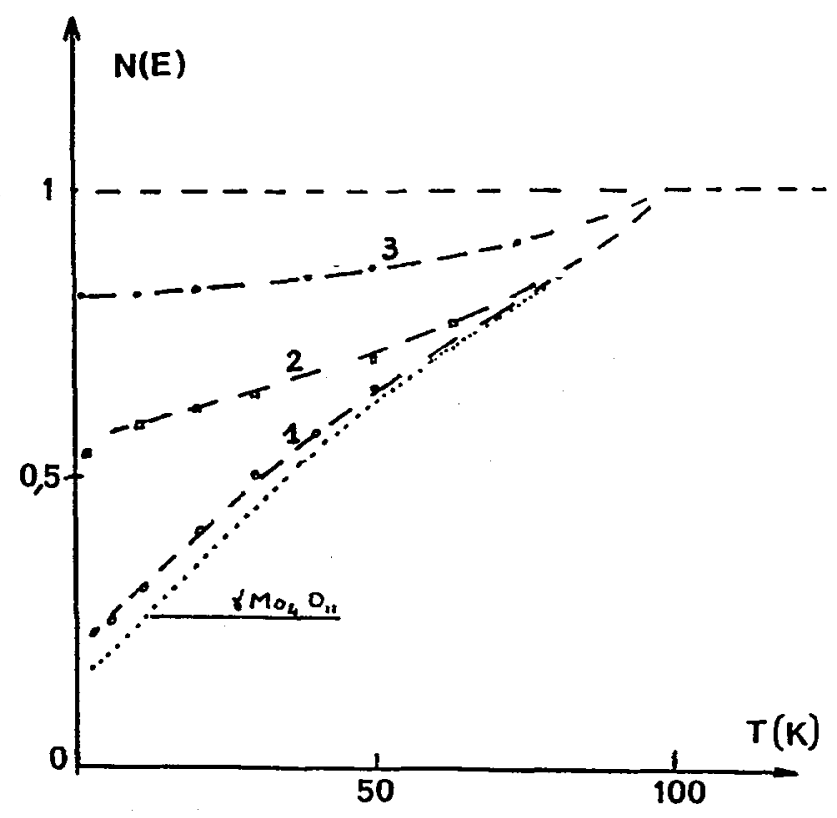

Figure 2: Evolution of condensation rates along different directions in $\eta$ Mo4O11 and in $\gamma$ Mo4011. 
In the aim to verify that the "gap" or "condensation at Fermi level" follow a BCS comportment with temperature we have supposed firstly that the shape oф condensation have a lorentzian form given by the following expression : $N(E)=\left(1-k c \Delta^{2} /\left(\Delta^{2}+E^{2}\right)\right) \quad$ formula in which $k c$ is the condensation rate at lowest temperature. Secondly we have supposed that $2 \Delta$ followed a BCS law versus temperature as: $\Delta(T)=\Delta(0)(1-(T / T P))^{1 / 2}$. We have introduced this expression in the classical formula giving the first derivative of tunneling current versus bias voltage (ref 2 ).We have plotted in figure 3 the results of simulation. The surprise is a good similitude between experimental results and computation.If we use a gaussian gap with the same parameter $k_{c}$ the simulation give a bad result. We are not able to explain this fact, and we hope that this analytic form of density of states could be a way for a theoritical work.

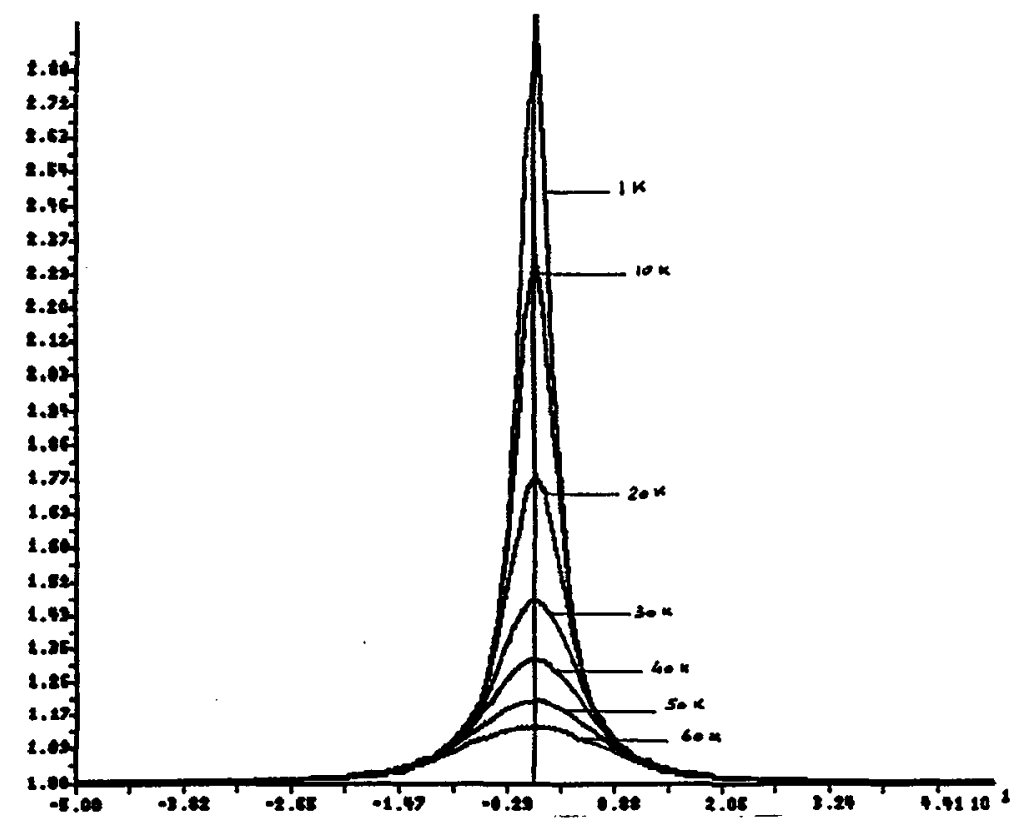

Figure 3: Simulation of $d V / d$ versus appied voltage with a lorentzian condensation References:

-1 H. GUYOT Thèse de doctorat Grenoble 1986 ;

H.GUYOT,C.SCHLENKER G.FOURCADOT, K.KONATE Solid State Com.

54(1984), 909

H.GUYOT,C. ESCRIBE-FILIPPINI,G.FOURCADOT,K.KONATE,C.SCHLENKER;J. Phys, C:Solid State Physi.16 (1983) L1127

-2 E.L. WOLF Principles of electron tunneling spectroscopy Oxford University Press 